\title{
STEREOTYPES AND PERCEPTIONS OF GENDER EQUALITY IN GLOBAL CORPORATIONS IN EUROPE AND THE USA - SUMMARY OF RESULTS FROM EUROPEAN COMPANIES
}

\author{
J. Stal-Le Cardinal $\bowtie$ \\ CentraleSupélec, France \\ $\triangle$ julie.le-cardinal@centralesupelec.fr
}

\begin{abstract}
While women are underrepresented in leadership across the industrial western world, there is a dearth of empirical evidence on how these stereotypes play out across cultural contexts, and their relative strengths. Our goal was to launch an ambitious comparative survey study of global corporations to increase knowledge on how gender stereotypes operate across cultures, and employee perceptions of gender equality in the workplace. The results provide a better understanding of the obstacles to women's professional development and identify levers for promoting gender diversity in large groups.
\end{abstract}

Keywords: complexity, human behaviour, empirical studies

\section{Introduction to the goals of the study and what's at stake}

The glass ceiling still hasn't been shattered and gender equality is far from being a reality in the workplace, both at SMEs and in international companies.

In this study, carried out in partnership with CentraleSupélec's Industrial Engineering Research Laboratory (LGI) and the Women Initiative Foundation (WIF), nearly 2400 managers and executives, men and women combined, were interviewed in 4 major groups (L'Oréal, BNP, ENGIE and ORACLE) in France, Germany and Italy.

These exclusive results have be shared with the Clayman Institute (Stanford) and compared to similar analyses conducted in the USA.

Our goal is to understand the situation and help balance in diversity.

The mission of the WIF is to become a key player in promoting the advancement of women in the workplace and in the economy.

The results provide a better understanding of the obstacles to women's professional development in large groups and identify levers for promoting gender diversity at all levels of the hierarchy. For the first time ever, a study of this magnitude compares the perceptions of men and women of different age groups in Europe on gender stereotypes and their perception of the equality climate in the workplace.

"Our goal in this research is not to make people feel guilty. Our objective is to present the facts observed in order to identify levers that would facilitate women's careers and, above all, allow the implementation of more egalitarian strategies in the company. We would all benefit from this," says Martine Liautaud, Founder and President of the Women Initiative Foundation. 
Our aim is to present the facts we observe and to shatter the clichés so as to enable each participating company to plan to improve its future. After a short state of the art, we will present our process that leads to our main results. There is no intention to make people feel guilty: men and women have the same stereotypes.

To give a short overview, main lessons are the following:

- Very similar gender stereotypes regardless of the respondents' sex or country

- The perception of a masculinization of women leaders

- Men much more optimistic than women about the climate of equality

- Family constraints perceived as the first obstacle to gender diversity

- Little gender difference in perception of company commitment, job satisfaction and work-life balance

\section{State of the art}

According to Caroline Simard, director of VMware Women's Leadership Innovation Lab at Stanford University, scholars have found that one of the most pervasive barriers to the advancement of women is the persistence of unconscious gender stereotypes, affecting evaluations of their competence (Eagly et al., 1992; Steinpreiss et al.,1999; Moss Racusin, 2013) This leads to an effect of cumulative disadvantage for women in the workplace, where even a slight disadvantage in evaluations can explain the underrepresentation of women in leadership positions (Martell, Lane, and Emrich, 1996).

Research on evaluations shows that our common and unconsciously held assumptions about women and men's competence at what we think of as "typical" male and female tasks shape our evaluations of their competence, often more so than their actual accomplishments. Men are implicitly assumed to be more competent at most tasks, and especially in what we think of as masculine domains (such as leadership) (Koenig et al., 2011) - a phenomenon known as "Think Leader, Think Male". Women are evaluated more harshly in these domains (even for eq xual accomplishment) and are held to a higher standard. Due to stereotypes, individuals are more likely to associate masculine attributes with leadership and more likely to see women as fitting a stereotype of "follower". Women tend to be perceived as having a "relationship orientation" whereas men are seen as having a "task orientation" (Braun et al., 2017). As they ascend to leadership, women tend to experience a likeabilty penalty (Fiske et al., 2019) for failing to adhere to expected gender roles.

While women are systematically underrepresented in leadership across the western world, there is a dearth of empirical evidence on how these stereotypes play out across cultural contexts, and their relative strengths. One study compared the UK, US, Germany, Japan, and China - which finds that while the nature of the stereotypes may vary slightly, across cultural contexts, respondents associate what they perceive as masculine traits with leadership (Schein et al., 1996). Our lack of understanding on how the similarities and variations in gender stereotypes in the workplace across cultural contexts leads to a lack of development of tailored interventions.

Our goal was to launch an ambitious comparative survey study of global corporations to increase knowledge on how gender stereotypes operate across cultures, and employee perceptions of gender equality in the workplace.

\section{Our methodology}

To get the most representative results possible, a large number of people (both men and women) were invited to participate in the study. A questionnaire was written up targeting on one hand stereotypes men and women have of men and women, and on the other hand perceptions of gender parity and discrimination in the workplace. The questionnaire was published online in summer 2017 for 4 global companies (L'Oréal, Oracle, Engie and BNPP) across 3 European countries (France, Germany and Italy).

\section{Our research question}

The main question underlying our research is to identify the obstacles to women's professional development, and consequently, to know how to improve gender parity at all levels. 
The study stands out from other research undertakings by several innovative characteristics. We interviewed the people concerned without any filter, and we analysed differences in perception by age range and by sex. We also considered hierarchical levels (senior executive or not) when analysing the stereotypes. Finally, we compare countries (France, Germany and Italy) and compare results with the United States for the similarities and differences that seem to us to be the most salient.

Lastly, our research was conducted in collaboration with the Women Initiative Foundation, expert on women in the workplace, CentraleSupélec's Industrial Engineering Research Department, for the industrial perspective, and Stanford University, research expert on gender issues. This tri-partite collaboration gives real validation to this experimental research

\section{Survey response}

The questionnaire has been completed online by men and women, managers and senior executives, at 4 global companies (Engie, L'Oréal, BNPP and Oracle), across 3 European countries (Germany, France and Italy).

The questionnaire response rate was significant, for both men and women. Over 2400 people responded:

- roughly 1000 in France, of which 72\% women and 28\% men,

- roughly 400 in Germany, of which $53 \%$ women and $47 \%$ men,

- roughly 1000 in Italy, of which $49 \%$ women and $51 \%$ men.

The number and the richness of the responses enabled us to conduct a comparative analysis by country and by company, with a focus on stereotypes and perception of gender parity in the company.

The sample of respondents offers a good balance, with 59\% of women respondents and $41 \%$ men. In Figure 1 shows that the populations over 35 years old responded more to the survey; their interest reflects the fact that the issue concerns them more.

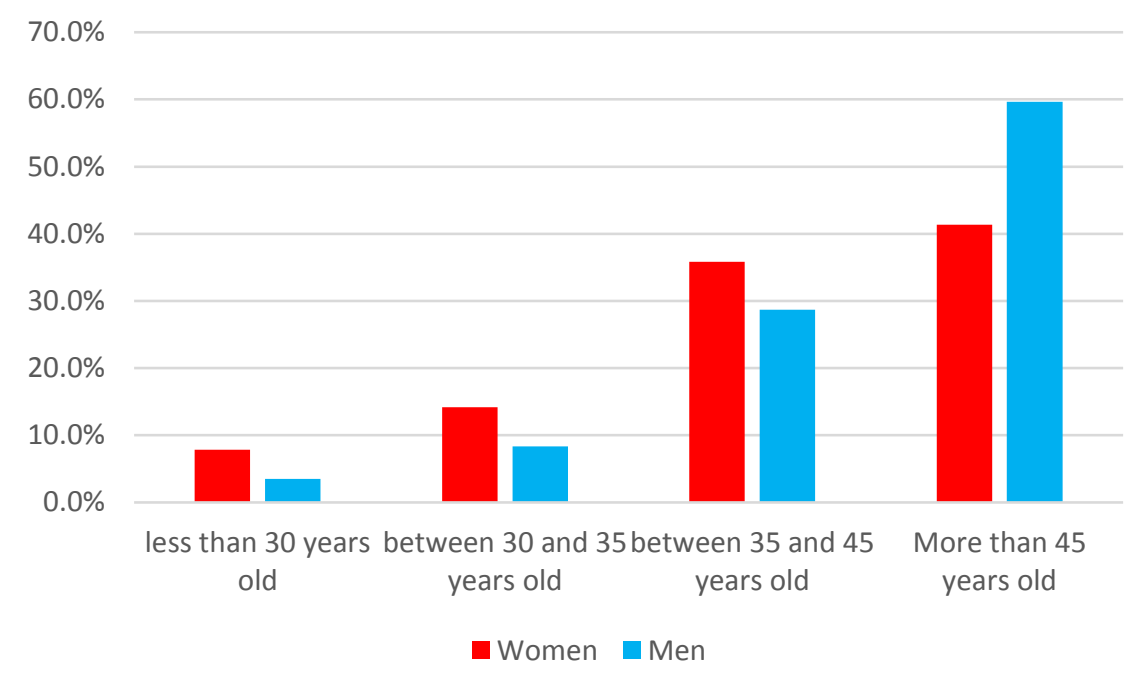

Figure 1. Age of respondents

Concerning the marital status of respondents:

- $18 \%$ of the women were single and $37 \%$ childless ( $48 \%$ in Germany),

- $12 \%$ of the men were single and $24 \%$ childless ( $26 \%$ in Germany).

Concerning their profile:

- $66 \%$ of the women and $42 \%$ of the men work in support functions;

- $34 \%$ of the women and $58 \%$ of the men work in operational or front-line jobs;

- $40 \%$ of the women and $45 \%$ of the men are managers;

- $92 \%$ of the women and $99.5 \%$ of the men work full-time. 


\section{Main results}

The results concern stereotypes men and women have of men and women, and perceptions of gender parity and discrimination in large corporations.

\section{Concerning stereotypes}

Stereotypes (in Figure 2) were measured by presenting a set list of 15 words; respondents ticked one or several words to complete the sentences, "Women/ Men are..."

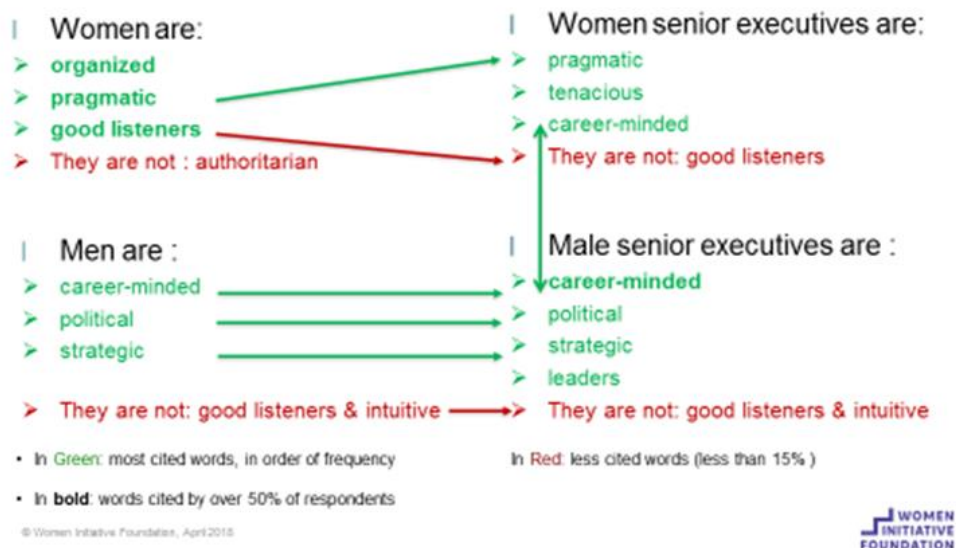

Figure 2. Gender stereotypes in Europe: Stereotypes were measured by presenting a set list of 15 words. Respondents ticked one or several words to complete the sentences: "Women/Men are..."

It turns out that men and women have stereotypes that are similar in the 3 countries. Stereotypes are identical for men regardless of hierarchical status, but they vary for women: women senior executives are seen as being more like men. We call this phenomenon the masculinization of senior executive women.

The reasons for masculinization of women are essentially self-censorship, jokes about women, the fact that less women seek power, and promoting women due to affirmative action policies. The reasons vary from country to country, for example self-censorship is less present in Italy. The main differences in stereotypes in Europe are as follows:

In France, stereotypes vary widely depending on hierarchical levels. Women senior executives are perceived as being quite different from women in general. The attributes associated with them are the same as for male senior executives; women executives become career-minded and don't listen well. These traits are attributed to men regardless of their hierarchical status. There is also a fundamental opposition between clichés of women in general and senior executives.

In Italy and in Germany, stereotypes do not vary according to hierarchical level. Women and women senior executives are perceived in the same way.

In Germany, women are equally considered career-minded, but not authoritarian.

In Italy, women are perceived as equally tenacious and poor listeners.

\section{Concerning the perception of gender parity}

In an attempt to deal with the subject as thoroughly as possible, we addressed the following themes: work-life balance, company experience, perceived equality, causes for the glass ceiling, and the masculinization of women senior executives.

Work-life balance is not a real gender issue; in the three countries there is little difference between men and women.

Indeed, nearly $80 \%$ of men and women declare they balance their personal and professional lives, even if it is far from simple for over half of them:

- Women declare a little less than men that they balance their lives (-7 points);

- Men and women who privilege their family lives are in the minority (7\% of men, $10 \%$ of women);

- In Germany, only $73 \%$ of women say they achieve work-life balance (compared to $80 \%$ in Italy and in France) and more women than men say they prioritize their professional lives 
( $22 \%$ compared to $15 \%$ ). Moreover $48 \%$ of them don't have children compared to 25 to $30 \%$ elsewhere. In Germany, family obligations are managed very early on!

Finally, $60 \%$ of respondents consider their work takes on too much importance:

- $58 \%$ of men and $62 \%$ of women think their work intrudes too much in their family live,

- Over half of both men and women feel guilty for not spending enough time with their family.

Company experience was studied from four angles: pride in belonging, women in management, the feeling of discrimination, and declining promotions. These are the main findings:

- Pride in belonging: $65 \%$ of women and $72 \%$ of men would recommend their company (rates higher by 10 points in Italy), while $73 \%$ of both men and women are proud of their job;

- Women in management: roughly $35 \%$ of women and $25 \%$ of men are managed by a woman, with significant variations depending on the company. This situation is thus highly positive.

- The feeling of discrimination varies widely depending on gender and country: $27 \%$ of women declared that they have been victims of negative discrimination, of which $13 \%$ several times (40\% of the victims in France) whereas $11 \%$ of men declared that they were discriminated against, of which 5\% several times (5\% of the victims in Germany).

- Declining promotions is more common for men: $16 \%$ of women and $23 \%$ of men have already turned down a post with greater responsibilities (in Germany the rates are higher by 10 points).

The perception of a culture of equality varies widely between countries, and large gaps between men's and women's perceptions is found in all countries (in Figure 3).

- In France equal opportunities are seen as being less favourable by men and women for remuneration, career development and also exemplarity in language used: almost $50 \%$ of women had heard jokes about women compared to only $15 \%$ in Germany and in Italy.

- However it's also in France that affirmative action for women is perceived the most $(40 \%$ of women and men compared with just $15 \%$ to $25 \%$ elsewhere).

- It's in Germany that a culture of equality is felt the most: over $50 \%$ of women perceive equal opportunities for promotions compared to less than a third who don't, and two thirds of women feel in as much demand as their male counterparts. This falls to 38\% in France. You will recall though in Germany that women are often (48\%) single and childless.

\begin{tabular}{|c|c|c|}
\hline & $\begin{array}{l}\text { Men } \\
\text { ( } \% \text { of YES) }\end{array}$ & $\begin{array}{l}\text { Women } \\
\text { ( } \% \text { of YES) }\end{array}$ \\
\hline Being a man or a woman is an important recruitment criteria & $14 \%$ & $33 \%$ \\
\hline With equal competencies, men are better paid than women & & \\
\hline Women have equal opportunities for internal promotion & $70 \%$ & \\
\hline We hear jokes about women & $15 \%$ & $27 \%$ \\
\hline Women are consulted as much as men for important decisions & $75 \%$ & $51 \%$ \\
\hline It's harder for women to become senior executives & $31 \%$ & \\
\hline Women are often favored due to the affirmative action policy & $29 \%$ & $22 \%$ \\
\hline Competent people are promoted regardless of their gender & $56 \%$ & $35 \%$ \\
\hline $\begin{array}{l}\text { I have enough opportunity to work on projects that are important for my } \\
\text { career development }\end{array}$ & $57 \%$ & $46 \%$ \\
\hline I have enough opportunities to excel & $55 \%$ & $47 \%$ \\
\hline
\end{tabular}

Figure 3. The perception of equality varies with gender 
Family constraints are identified by both women and men as the number one reason for the glass ceiling in all countries (in Figure 4).

- It's in that Germany family constraints have the most impact (cited by $85 \%$ of respondents compared with $70 \%$ to $75 \%$ elsewhere).

- Women needing to prove themselves more than men is perceived to be the case by over half of Europeans. For men, the glass ceiling is essentially linked to family constraints.

- In Italy self-censorship by women and the fact that less women seek power is rarely cited, unlike in France and in Germany. 30\% of Italian women compared to two thirds of German and French women cite self-censorship, $18 \%$ cite attraction to power compared to $35 \%$ elsewhere.

\begin{tabular}{|c|c|c|}
\hline Why are there less women in senior positions? & Men & Women \\
\hline \multicolumn{3}{|l|}{ As family responsibilities slow down their careers } \\
\hline As they self-censor or have less confidence in themselves & $26 \%$ & \\
\hline As they have to prove their skills more & $37 \%$ & $64 \%$ \\
\hline As their superiors favor men & $33 \%$ & $50^{\circ}$ \\
\hline \multicolumn{3}{|l|}{ As they are less attracted to power than men } \\
\hline As they chose career paths that don't lead to top management & $19 \%$ & $30 \%$ \\
\hline As they don't take enough risks & $10 \%$ & $20 \%$ \\
\hline As they need to accept international posts to move upwards & $12 \%$ & $9 \%$ \\
\hline As they aren't confident enough to give opposing opinions in meetings & $4 \%$ & $4 \%$ \\
\hline As they cope less well with stress than men & $5 \%$ & $5 \%$ \\
\hline
\end{tabular}

Figure 4. The reasons for the glass ceiling differ according to gender

Finally, regarding the masculinization of women senior executives, the main points to remember are:

- $46 \%$ of women and $47 \%$ of men believe that women that are appointed to posts of high responsibility end up behaving like men.

- In France, 52\% of women perceive such masculinization, in Italy 56\% of men notice it.

- This masculinization of women senior executives is essentially seen by the fact that they become more career-minded than men and tougher in their management style.

- The perception of masculinization is linked to stereotypes of women senior executives (in particular in France).

- This perception makes it hard for women to project themselves in senior executive posts, and calls role models into question.

\section{Opening up to the USA}

Using McKinsey\&Company's LeanIn report, enriched by discussions with the Clayman Institute (Stanford), we highlight the main similarities and differences between Europe and the United States.

Then main differences concern the lack of an American policy supporting maternity (only 3 countries in the world, of which one is the USA, do not have a maternity support program) and life-work balance. Indeed, in the USA women still manage the home, even with a full-time job.

The stark differences in the perceptions of women and men in their perceptions of equality also echoes the US findings. That is, men perceive the workplace as being more "fair" than women do (Figure 4). This perception gap is critical for companies to address - through targeted interventions, companies can measure 
gaps year over year to ensure a more equal cultural experience. Women in the WIF sample are especially aware of the promotion and wage gaps at play in organizations. Similarly, in the US, women see their gender as being a factor in being less likely to be promoted and get equal pay (McKinsey/Lean In, 2017).

- Nearly $50 \%$ of men think women are well represented in leadership in organizations where only $\mathbf{1}$ in 10 senior leaders is a woman.

$$
\begin{aligned}
& \dot{x} \boldsymbol{x} \dot{x} \\
& \dot{x} \hat{x} \boldsymbol{x} \dot{x}
\end{aligned}
$$

- Men think their company is doing a better job on gender diversity, and are less personally committed to diversity.

- $15 \%$ of men feel that gender diversity efforts disadvantage them, that their gender is a barrier to advancement. (Similar to view of affirmative action in France.)

"Based on "Women in the Workplace" report, Lean In and McKinsey\&Company, 2017.

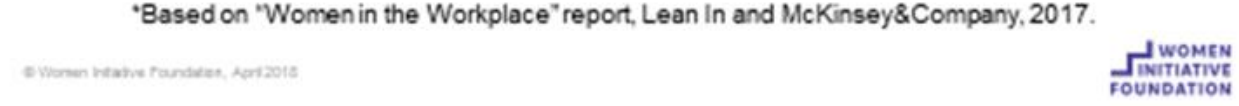

Figure 5. Men think women are doing better than they really are.

The larger gaps in the French sample seem to match the strength of the role incongruency stereotypes shown by the study - women experience negative comments, and a lack of access to career development, as well as a backlash from affirmative action policies). In Germany, the perception of equality is likely equally related to the better role congruency (for those women who remain in the workplace).

The main similarities are the following:

- stereotypes of women;

- the perception of engagement in companies;

- men (American and Europeans) think the system encourages women more;

- women (American and Europeans) have no intention of leaving their job for family reasons;

- the masculinization of women senior executives (huge similarity between France and the USA)

- the feeling of discrimination (40\% in France and 37\% in the USA).

\section{Conclusion}

We have set out a summary of the main findings and lessons from the study conducted on stereotypes and perceptions of gender parity in large corporations. Detailed results can be found on WIF website: http://women-initiative-foundation.com/fr/accueil/

Conclusions concerning stereotypes are as follows:

- Men and women have very similar stereotypes in the 3 countries;

- Women senior executives often behave like men (senior executive or otherwise).

Regarding perceptions of a culture of equality in companies:

- There is little difference between men and women regarding employee engagement and worklife balance;

- There are marked differences between men and women regarding perceptions of why the glass ceiling remains and the feeling of discrimination.

Following this research, WIF proposes to create a voluntary mentoring program for young high potentials (under 40s). The program would leverage the positive points observed in the various countries. 
One of the short term perspectives is to design and roll out an ambitious intercompany mentoring program for under-40-year-old high potential women, initially in Europe, then internationally.

The one-year program will offered tailored mentoring for each mentee, with particular attention paid to the choice of men or women mentors. The goal of the program is to enable women move on in their careers by helping them to better understand how to improve their opportunities and their visibility.

WIF will also offer large companies advice and concrete measures to improve gender parity, based on this research and the specificities of each company. The scope will be France, Europe, Canada and the USA.

Longer-term action concerns the training of women, women engineers and future leaders.

CentraleSupélec, as a leading engineering school, is increasingly concerned by this problem and supports the creation of training programs for women leaders in engineering schools and in continuing education.

We are confident that this type of research, coupled with new educational programs, can make a difference in the perception and stereotyping of diversity.

To open the discussion, we also can ask ourselves what consequences could be derived from this first research on stereotypes. Is it possible to establish a stronger relationship with engineers?

Do the stereotypes of engineers differ from general stereotypes?

\section{Acknowledgement}

This study is empirical.

It is based only of perception of men and women about women in the workplace.

This explains the lack of references.

Thank you to Caroline Simard, PhD, Stanford University, VMware Women's Leadership Innovation Lab for her help in this study and especially for the comparison with the US.

\section{References}

Braun, S. et al. (2017), "Think manager-think male, think follower-think female: Gender Bias in implicit Followership Theories", Journal of Applied Social Psychology, Vol. 47 No. 7, pp. 377-388.

Eagly, A., Makhijani, M. and Klonsky, B. (1992), "Gender and the Evaluation of Leaders: A MetaAnalysis", Psychological Bulletin - The American Psychological Association Inc., 1992, Vol. 111 No. 1, pp. 3-22.

Fiske, S. et al. (2019), "A Model of (often mixed) Stereotype Content: Competence and warmth respectively follow from perceived Status and Competition", Journal of Personality and Social Psychology.

Koenig, A.M. et al. (2011), "Are Leader Stereotypes Masculine? A Meta-Analysis of Three Research Paradigms", Psychological Bulletin, American Psychological Association, Vol. 137 No. 4, pp. 616-642.

Martell, R., Lane, D. and Emrich, C. (1996), "Male-Female Differences: A Computer Simulation", American Psychologist, Vol. 51 No. 2, pp. 157-158.

Moss Racusin, C. (2013), "Gender Bias Also Contributes to the Attrition of Women in Science", BioScience, Vol. 63 No. 5, p. 318.

Schein, V. et al. "Think manager - think Male: a global phenomenon?", Journal of Organizational Behavior, Vol. 17 No. 1, pp. 33-41.

Steinpreiss, R., Anders, K. and Ritzke, D. (1999), "The Impact of Gender on the Review of the Curricula Vitae of Job Applicants and Tenure Candidates: A National Empirical Study", Sex Roles, Vol. 41 No. 7-8, pp. 509-528.

"Women in the Workplace", report by LeanIn.org and McKinsey\&Company, 2017. 